\title{
Fragmentation Processes of Some Thiocarbonyl Compounds on Electron Impact*
}

\author{
A. M. DUFFIELD and CARL DJERASSI \\ Department of Chemistry, Stanford University, Stanford, Calif., U.S.A. \\ J. SA N D S T R ö M \\ Department of Organic Chemistry, University of Lund, Lund, Sweden
}

\begin{abstract}
The mass spectra of fourteen thiocarbonyl compounds are reported and discussed. The fragmentation of these compounds was generally explicable in terms of simple bond cleavage processes with and without hydrogen rearrangement although in several instances unexpected skeletal rearrangements did occur.
\end{abstract}

The mass spectrometric fragmentation of carbonyl compounds has been 1 extensively investigated ${ }^{1}$ especially with regard to hydrogen transfer processes of which the principal mode is the well-documented McLafferty rearrangement. ${ }^{2}$ More recently the elimination of carbon monoxide and carbon dioxide from various carbonyl compounds has been observed ${ }^{3}$ while sulphur compounds have shown some facility in suffering skeletal rearrangements under electron impact conditions. ${ }^{4}$ Thus it was of interest to examine the mass spectra of a series of thiocarbonyl compounds that had been prepared recently ${ }^{5}$ in order to ascertain whether this class of compounds might undergo rearrangements of groups other than hydrogen upon electron impact and if possible to define the scope and limitations of these processes.

* Part CXXXVIII of a series of papers "Mass Spectrometry in Structural and Stereochemical Problems". For Paper CXXXVII see: Green, M. M. and Djerassi, C. J. Am. Chem. Soc. In press. 


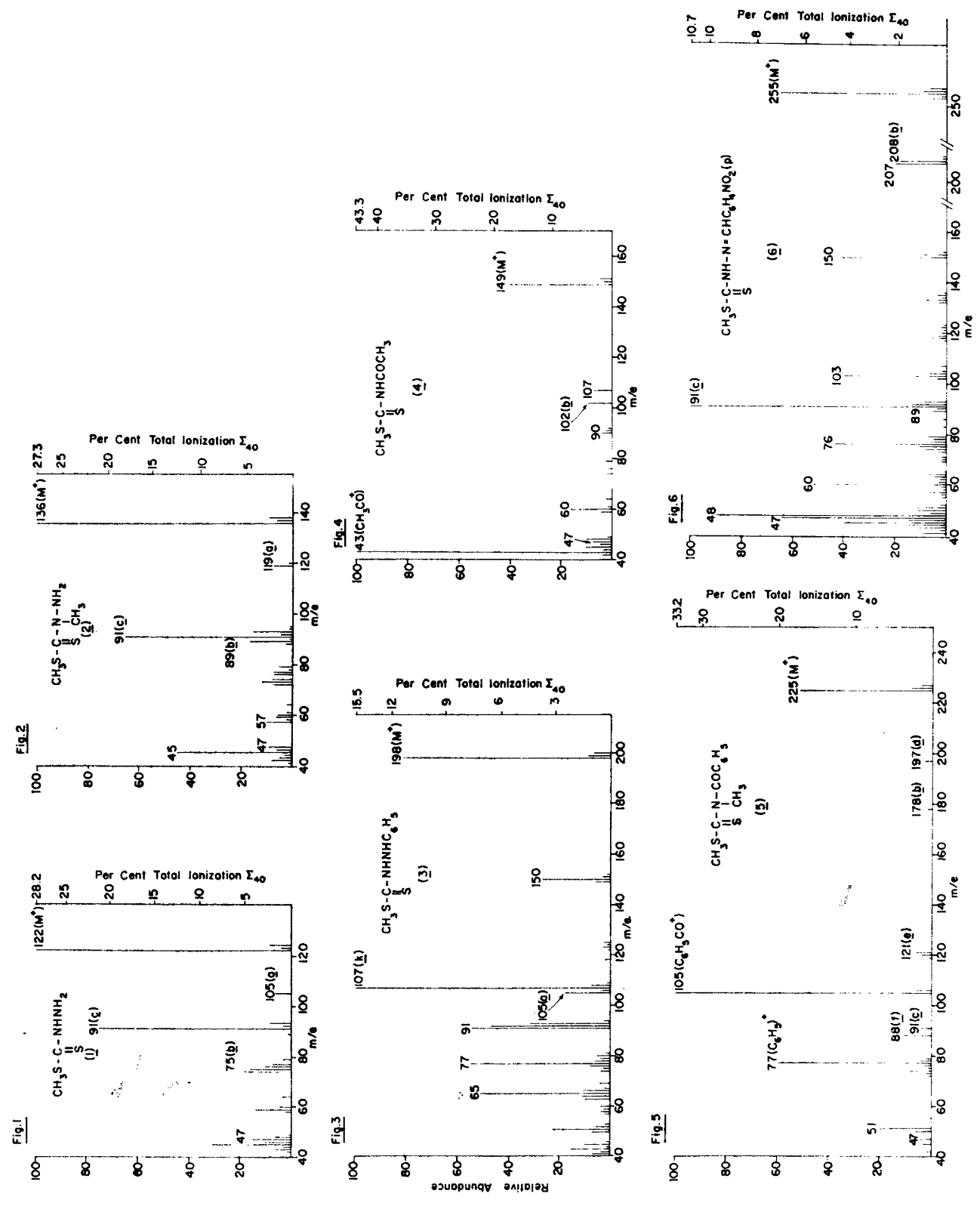

Acta Chem. Scand. 21 (1967) No. 8 


\section{AMIDES OF DITHIOCARBONIC ACID}

$$
\begin{aligned}
& \mathrm{CH}_{3} \mathrm{~S}-\stackrel{\mathrm{C}}{\mathrm{C}}-\mathrm{N}^{\prime}>_{\mathrm{R}}^{\mathrm{R}^{\prime}} \\
& \text { (1) } \mathrm{R}=\mathrm{H}, \mathrm{R}^{\prime}=\mathrm{NH}_{2} \\
& \text { (2) } \mathrm{R}=\mathrm{CH}_{3}, \mathrm{R}^{\prime}=\mathrm{NH}_{2}
\end{aligned}
$$

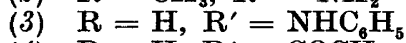

$$
\begin{aligned}
& \text { (4) } \mathrm{R}=\mathrm{H}, \mathrm{R}^{\prime}=\mathrm{COCH}_{\mathbf{3}} \\
& \text { (5) } \mathrm{R}=\mathrm{CH}_{3}, \mathrm{R}^{\prime}=\mathrm{COC}_{6} \mathrm{H}_{5} \\
& \text { (6) } \mathbf{R}=\mathbf{H}, \mathbf{R}^{\prime}=\mathbf{N}: \mathrm{CHC}_{6} \mathrm{H}_{4} \mathrm{NO}_{2}-(p)
\end{aligned}
$$

All six substituted amides of dithiocarbonic acid $(1-6)$ have mass spectra (Figs. 1-6) in which the molecular ion is of appreciable intensity. An interesting fragmentation in the case of compounds 1 and 2 is the elimination of ammonia from the molecular ion (the appropriate metastable ion is observed in both instances) and this process can be rationalized by $1 \rightarrow a$. The elimination of ammonia from organic compounds upon electron impact is not a common process although it has been observed in the fragmentation of salicylamide. ${ }^{6}$ Substitution of one of the terminal amino hydrogen atoms by phenyl as in 3 does not change this mode of fragmentation since a peak at $m / e 105$ in Fig. 3 now points to the elimination of the elements of aniline rather than of ammonia.<smiles>[R]N(C(=S)SCC)[Y9]([Y])([H])CC</smiles>

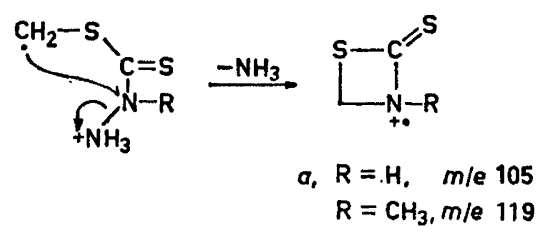

A peak occurs at $\mathrm{M}-47$ in compounds $1,2,4,5$, and 6 which corresponds to the elimination of $\mathrm{CH}_{3} \mathrm{~S}$ such that the general form of the charged entity is depicted by $b$. It is noteworthy that in this fragmentation a portion of the ion yield can also be accomodated by the thiomethyl species yielding peaks at $m / e \quad 47\left(\mathrm{CH}_{3} \mathrm{~S}^{+}\right)$in all spectra. These conclusions are not valid for 3 and no readily apparent reason for this exception can be seen.<smiles></smiles>

The alternate $\alpha$-cleavage to the carbonyl sulphur atom promotes the ubiquitous $m / e 91$ peak in the spectra of compounds $1-6$ and this can be represented by $c, m / e 91$.

Acta Chem. Scand. 21 (1967) No. 8

$$
\begin{gathered}
\mathrm{CH}_{3} \mathrm{~S}-\mathrm{C} \equiv \stackrel{+}{\mathrm{S}} \\
c, m / e \mathrm{91}
\end{gathered}
$$


An interesting fragmentation, found only in compound 5 , is the loss of carbon monoxide from the molecular ion generating the peak at $m / e 197$ in the spectrum (Fig. 5) of compound 5. This fragmentation remained at low electron voltage $(14 \mathrm{eV})$ and high resolution mass spectrometry verified that this ion did indeed arise from the expulsion of carbon monoxide from the molecular ion. A rationalization for the genesis of this ion would be transfer of a phenyl group through a five-membered intermediate to the carbonyl sulphur atom $(5 \rightarrow d, m / e$ 197). It is noteworthy that the mass spectrum (Fig. 7) of the methoxy thiocarbonyl amide 7 contains a peak at $m / e 105(\mathrm{M}-\mathrm{CO})$ which must arise from a similar decomposition as depicted by $5 \rightarrow d$ except that the migrating entity is now a methyl radical.

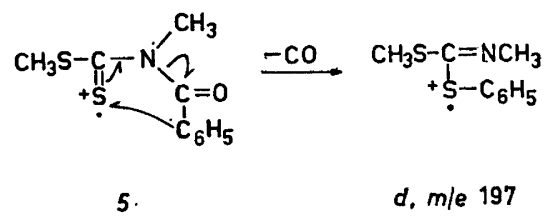

High resolution mass spectrometry established the composition $\mathrm{C}_{7} \mathrm{H}_{5} \mathrm{~S}$ $(25 \%)$ and $\mathrm{C}_{3} \mathrm{H}_{7} \mathrm{NS}_{2}(75 \%)$ for the ion of mass 121 in the spectrum (Fig. 5) of compound 5 . The minor component of the doublet must arise from a skeletal rearrangement process and one possibility would be decomposition of the species $d$ although no reasonable mechanistic rationalization is apparent for what must be a very bizarre process. The major constituent of mass 121 could arise from either loss of benzyne from $d$ or by the elimination of $\mathrm{C}_{6} \mathrm{H}_{4} \mathrm{CO}$ from the molecular ion. No metastable ion was found to confirm the occurrence of either process but it was observed that at low electron energy $(14 \mathrm{eV})$ the peak at $\mathrm{m} / \mathrm{e} 121$ did become markedly less abundant than other fragment ions suggesting that it arose by a secondary decomposition process such as that represented by $d \rightarrow e(m / e 121)$.

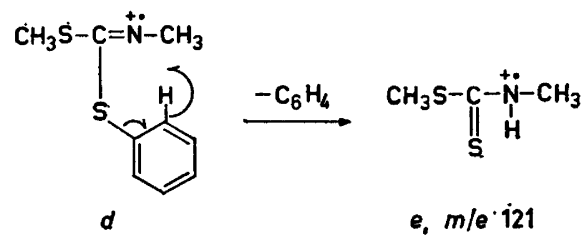

The ion of mass $88\left(\mathrm{C}_{3} \mathrm{H}_{6} \mathrm{NS}\right.$ by high resolution mass measurement) in the spectrum (Fig. 5) of compound 5 remained prominent at low electron energy $(14 \mathrm{eV})$ suggesting that it arose from a primary decomposition of the molecular ion. One such rationalization is depicted by $5 \rightarrow f(m / e 88)$.

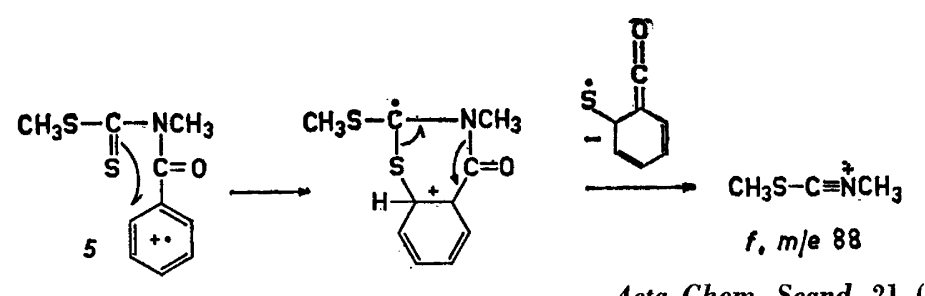

Acta Chem. Scand. 21 (1967) No. 8 
The presence of the benzoyl cation $\left(\mathrm{C}_{6} \mathrm{H}_{5} \mathrm{CO}^{+}\right)$at mass 105 and the phenyl ion at mass 77 in the spectrum (Fig. 5) of compound 5 require no comment.

AMIDES OF METHOXYTHIOCARBONIC ACID

$\mathrm{CH}_{3} \mathrm{O}-\stackrel{\mathrm{S}}{\|}-\mathrm{NHR}$

(7) $\mathrm{R}=\mathrm{COCH}_{3}$

(8) $\mathrm{R}=\mathrm{NHC}_{6} \mathrm{H}_{5}$

(9) $\mathrm{R}=\mathrm{NHCOCH}_{3}$
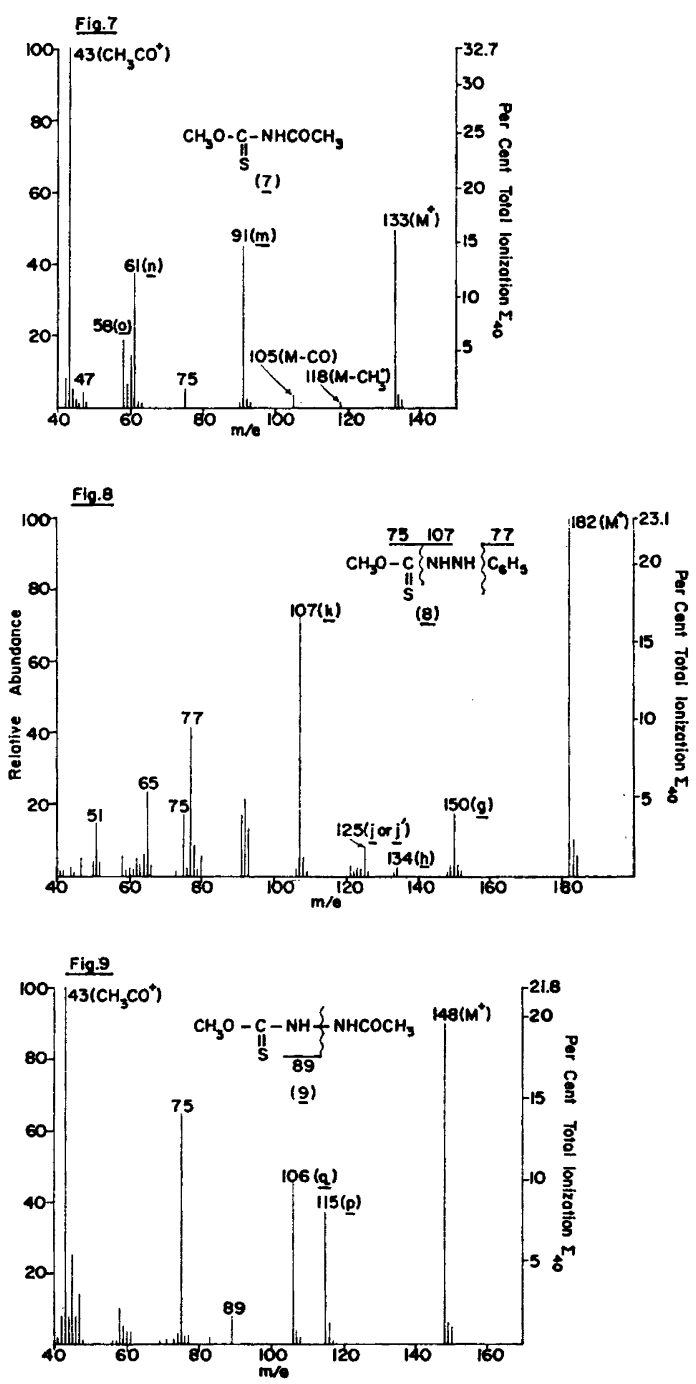

Acta Chem. Scand. 21 (1967) No. 8 
The mass spectra (Figs. 7-9) of the three amides of methoxy thiocarbonic acid (compounds $7-9$ ) all display abundant molecular ion peaks. The most interesting fragmentation pattern is produced by compound 8 and its mass spectrum will be discussed in some detail.

The peak at $m / e 150\left(\mathrm{C}_{7} \mathrm{H}_{6} \mathrm{~N}_{2} \mathrm{~S}\right.$ by high resolution) in the spectrum (Fig. 8) of 8 arises from the elimination of methanol from the molecular ion (metastable ion at mass $123.6 ; 150^{2} / 182=123.6$ ). Such a process can be rationalized by $8 \rightarrow g,(m / e$ 150) and this is supported by the occurrence of a weak peak at $m / e 116\left(\mathrm{M}-\mathrm{CH}_{3} \mathrm{OH}\right.$ ) (larger than the ${ }^{13} \mathrm{C}$ isotope contribution from $m / e$ 115) in the spectrum (Fig. 9) of the amide 9. Significantly, the thiocarbonyl derivative 7 , in which no hydrazine-type hydrogen is located for the transfer envisaged in $8 \rightarrow g$, lacks a peak (Fig. 7) corresponding to the elimination of methanol.

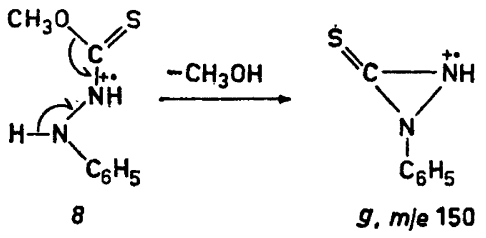

It is noteworthy that the thiocarbonyl compounds $1-6$ which contain the $\mathrm{SCH}_{3}$ group all showed loss of this entity in their mass spectra (ion $b$ ) while none of the methoxy substituted derivatives 7-9 displays any loss of $\mathrm{OCH}_{3}$ from the molecular ion.

A weak peak at $m / e 134(M-48)$ in the spectrum (Fig. 8) of the amide 8 must arise from the expulsion of $\mathrm{CH}_{3} \mathrm{SH}$ from the molecular ion. Such a process may be rationalized by the sequence $8 \rightarrow h,(m / e 134)$, which assumes the intervention of a tautomeric species $8 a$.

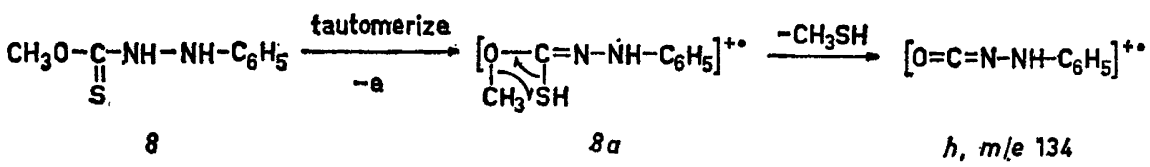

High resolution mass spectrometry established the composition $\mathrm{C}_{6} \mathrm{H}_{7} \mathrm{NS}$ for the ion of mass 125 in Fig. 8. A metastable ion at mass $85.9\left(125^{2} / 182=85.9\right)$ indicated that this fragment arose from a one step decomposition from the parent ion while at low electron energy this fragment was still present. Furthermore, the spectra (Figs. 12 and 13) of the thiocarbonyl compounds 12 and 13 (see below) which contain the common grouping $\stackrel{\|}{\mathrm{C}}-\mathrm{NHNHC}_{6} \mathrm{H}_{5}$ exhibit an ion $\left(\mathrm{C}_{6} \mathrm{H}_{7} \mathrm{NS}\right)$ of mass 125 . Consequently, it must arise by a skeletal rearrangement process and one rationalization is depicted through the tautomer $8 a$ giving $j(m / e$ 125). The alternative possibility of the transfer of the sulphydryl 
radical in $8 a$ through a four-membered ring with the production of $j^{\prime}(m / e$ 125) is, of course, not excluded.

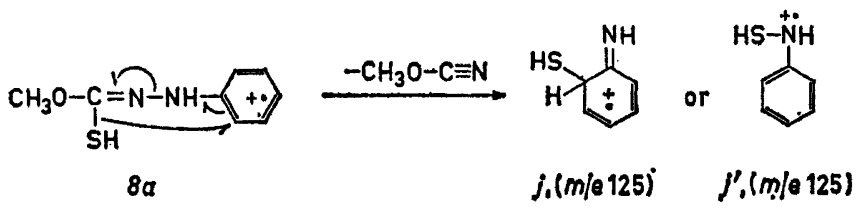

The prominent peak at $m / e 107(\mathrm{M}-75)$ in the spectrum (Fig. 8) of compound 8 corresponds to the ion $k$ resulting from fission of the carbon-nitrogen bond. It is noteworthy that in this fragmentation the charge can also be retained by the other cleavage product yielding an ion of mass $75\left(\mathrm{C}_{2} \mathrm{H}_{3} \mathrm{SO}\right)$ in Fig. 8 and Fig. 9. This ion also occurs in the spectra (Figs. 7 and 9) of the analogous compounds 7 and 9 .

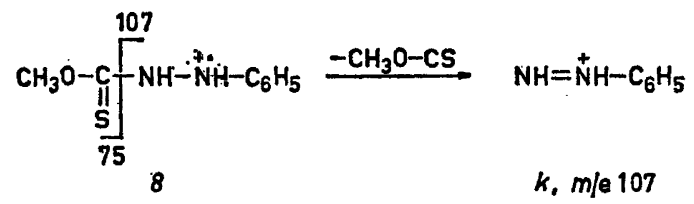

The McLafferty rearrangement ${ }^{2}(7 \rightarrow m / e$ 91) is probably responsible for the peak at $m / e 91(\mathrm{M}-42)$ in the spectrum (Fig. 7) of the methoxy thiocarbonyl derivative 7 although a four centered transition state with hydrogen transfer to the nitrogen atom is not excluded $(c f .9 \rightarrow q)$ while the further loss of formaldehyde from the species $m$ would yield $n,(m / e$ 61). An alternative fragmentation mode for the species $m$ is the loss of the sulphydryl radical and production of $o,(m / e 58)$.

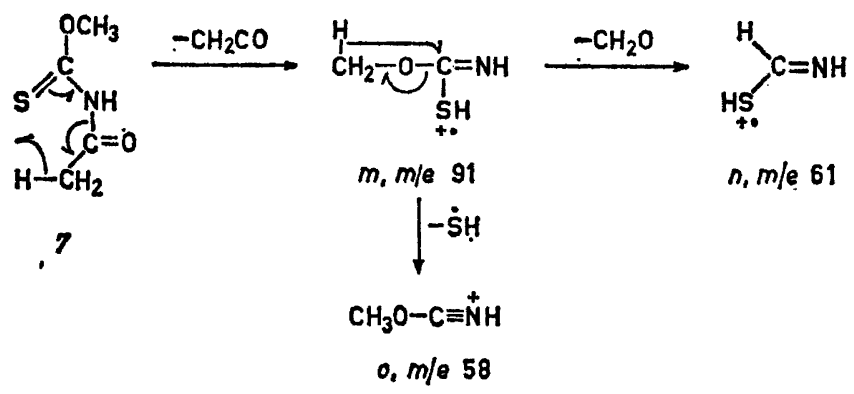

The mass spectrum (Fig. 9) of the $\mathrm{N}$-acetyl hydrazine derivative 9 contains an abundant peak at $m / e 115(\mathrm{M}-33)$ which arises directly from the molecular ion (a metastable ion at mass 89.4 was recognized; $115^{2} / 148=89.4$ ) by loss of a sulphydryl radical. Intervention of the tautomeric molecular ion $9 a$ is a likely explanation for the production of $p$

Acta Chem. Scand. 21 (1967) No. 8 


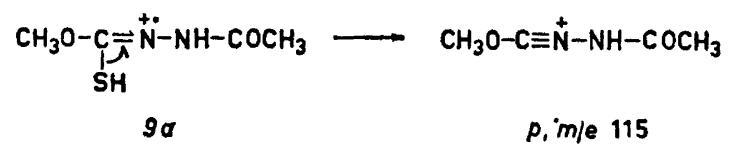

Elimination of 42 mass units from the molecular ion of 9 yields the ion of mass 106 in Fig. 9. A plausible rationalization for the formation of this ion would be by loss of ketene from the molecular ion as envisaged in $9 \rightarrow q$, $(m / e$ 106).

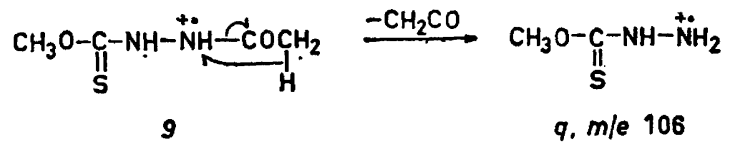

N,N'-DIACETYL THIOUREA<smiles>COC(=O)NC(=S)NOC(C)=O</smiles>

10

$\mathrm{N}, \mathrm{N}^{\prime}$-Diacetyl thiourea $(10)^{7}$ yields a mass spectrum (Fig. 10) which can easily be rationalized by well established fragmentation modes. Thus the most intense peak $\left(m / e\right.$ 43) corresponds to $\mathrm{CH}_{3} \mathrm{CO}^{+}$and the strong peak at $m / e 59$ to the species $r,(m / e 59)$ since this ion lacks sulphur as no ${ }^{34} \mathrm{~S}$ isotope peak at $m / e 61$ was observed. Peaks at $m / e 118$ and 76 have the compositions $\mathrm{C}_{3} \mathrm{H}_{6} \mathrm{~N}_{2} \mathrm{OS}$ and $\mathrm{CH}_{4} \mathrm{~N}_{2} \mathrm{~S}$ and the genesis of these ions can be rationalized by successive McLafferty rearrangements ${ }^{2}$ or by successive four-centered intermediates such as $9 \rightarrow q$. The appropriate metastable ions for these decompositions were observed at mass $87.0\left(118^{2} / 160=87.0\right)$ and $48.9\left(76^{2} / 118=48.9\right)$.

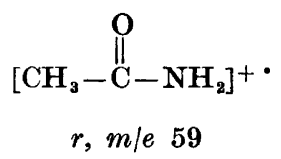

A weak peak at $m / e 132(\mathrm{M}-28)$ in the spectrum (Fig. 11) of $\mathrm{N}, \mathrm{N}^{\prime}$-diacetylthiourea $(10)$ corresponds by high resolution mass spectrometry to the elimination of carbon monoxide. Recognition of a metastable ion at mass 108.9 $\left(132^{2} / 160=108.9\right)$ verified that this ion resulted from an electron impact promoted fragmentation which must involve a methyl migration and is thus analogous to the loss of carbon monoxide from compound 7 ( $m / e 105$ in Fig. 7). 

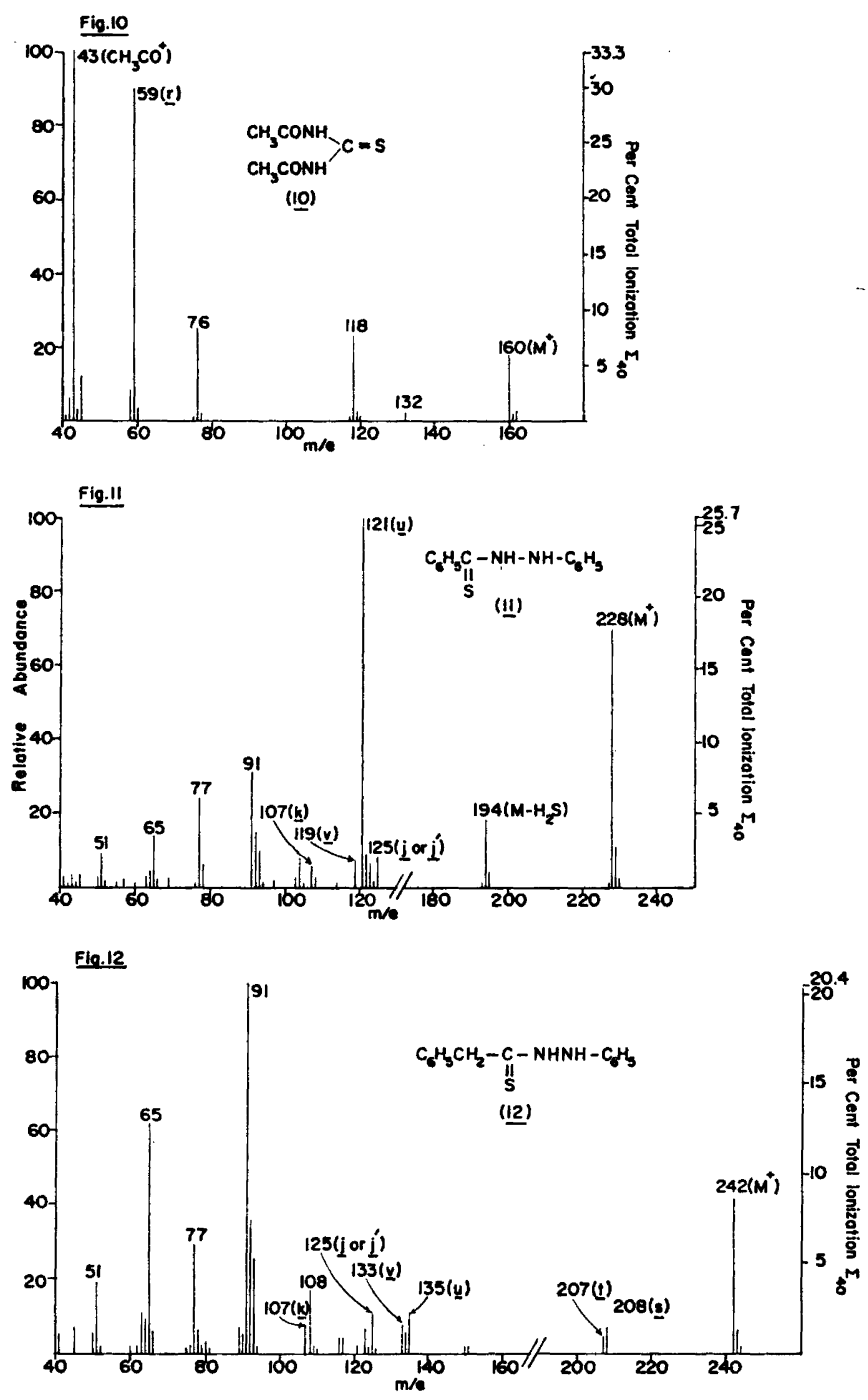

N-PHENYLTHIOHYDRAZIDES

(11) $\mathrm{C}_{6} \mathrm{H}_{5}-\stackrel{\mathrm{S}}{\mathrm{C}}-\mathrm{NH}-\mathrm{NH}-\mathrm{C}_{6} \mathrm{H}_{5}$

(12) $\mathrm{C}_{6} \mathrm{H}_{5} \mathrm{CH}_{2}-\stackrel{\mathrm{S}}{\mathrm{C}}-\mathrm{NH}-\mathrm{NH}-\mathrm{C}_{6} \mathrm{H}_{5}$ 
The mass spectra (Figs. 11 and 12) of the phenylhydrazine derivatives 11 and 12 contain strong peaks due to the respective molecular ions while the loss of hydrogen sulphide surprisingly yields peaks of appreciable intensity in each instance. The composition of the ion (high resolution mass spectrometry) of mass 208 in the spectrum (Fig. 12) of compound 12 was indeed compatible with the elimination of hydrogen sulphide from the molecular ion such that the charged entity might be written as $s, m / e$ 208. The facile loss of a hydrogen atom from an $\mathrm{M}-\mathrm{H}_{2} \mathrm{~S}$ precursor in the benzyl derivative 12 (metastable ion at mass $206 ; 207^{2} / 208=206$ ) can be interpreted in terms of the formation of the highly conjugated even-electron species $t,(m / e 207)$.<smiles>[R]C1=NN1c1ccccc1</smiles>

$s,\left(\mathrm{R}=\mathrm{C}_{6} \mathrm{H}_{5}, m / e \quad 194\right)$

$\left(\mathrm{R}=\mathrm{C}_{6} \mathrm{H}_{5} \mathrm{CH}_{2}, m / e\right.$ 208)

$$
\mathrm{C}_{6} \mathrm{H}_{5} \mathrm{CH}=\mathrm{C}=\stackrel{+}{\mathrm{N}}=\mathrm{N}-\mathrm{C}_{6} \mathrm{H}_{5}
$$$$
t, m / e 207
$$

The ion of mass 125 in the spectra (Figs. 11 and 12) of the N-phenylthiohydrazides 11 and 12 has been shown (see above) to involve a skeletal rearrangement in its formation and has been assigned structure $j$ or $j^{\prime}$.

Cleavage of the molecular ion $\alpha$ to the thiocarbonyl group can be noted in both 11 and 12 and the resulting species assigned structure $u$. This cleavage is much more pronounced in 11 ( $\mathrm{m} / \mathrm{e} 121 \mathrm{in} \mathrm{Fig.} 11)$ as compared to $12 \mathrm{(m} / \mathrm{e}$ 135 in Fig. 12), presumably because of the latter's competitive fission to the tropylium ion $(m / e$ 91).

$$
\begin{aligned}
& \mathrm{R}-\mathrm{C} \equiv \stackrel{+}{\mathrm{S}} \\
& u,\left(\mathrm{R}=\mathrm{C}_{6} \mathrm{H}_{5}, m / e \quad 121\right) \\
&\left(\mathrm{R}=\mathrm{C}_{6} \mathrm{H}_{5} \mathrm{CH}_{2}, m / e \quad 135\right)
\end{aligned}
$$

Ions of low abundance at mass 119 and 133 in the spectra of compounds 11 and 12 correspond to the unexpected elision of $\mathrm{C}_{6} \mathrm{H}_{5} \mathrm{~S}$ from the respective molecular ions and this was verified by high resolution mass spectrometry in the case of the benzyl thiocarbonyl derivative 12. One representation for these ions is depicted by $v$.

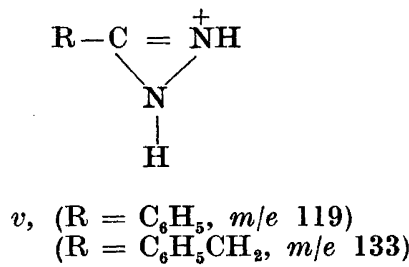


A peak at m/e 107 in the spectra (Figs. 11 and 12) of both the phenyl hydrazine derivatives 11 and 12 corresponds to the ion $k$ and requires no comment, while that at $m / e 108$ in these spectra is almost certainly the phenyl hydrazine ion radical.

\section{THIOHYDRAZONES}

(13)<smiles>CN(/N=C/c1ccccc1)C(=S)c1ccccc1</smiles>

(14)<smiles>CC(C)=NNC(=S)c1ccccc1</smiles>

The mass spectra (Figs. 13 and 14) of the two thiohydrazones 13 and 14 contain intense ions ( $w$ in the case of 13) arising from the elimination of a phenyl and methyl radical, respectively, from the molecular ion even though

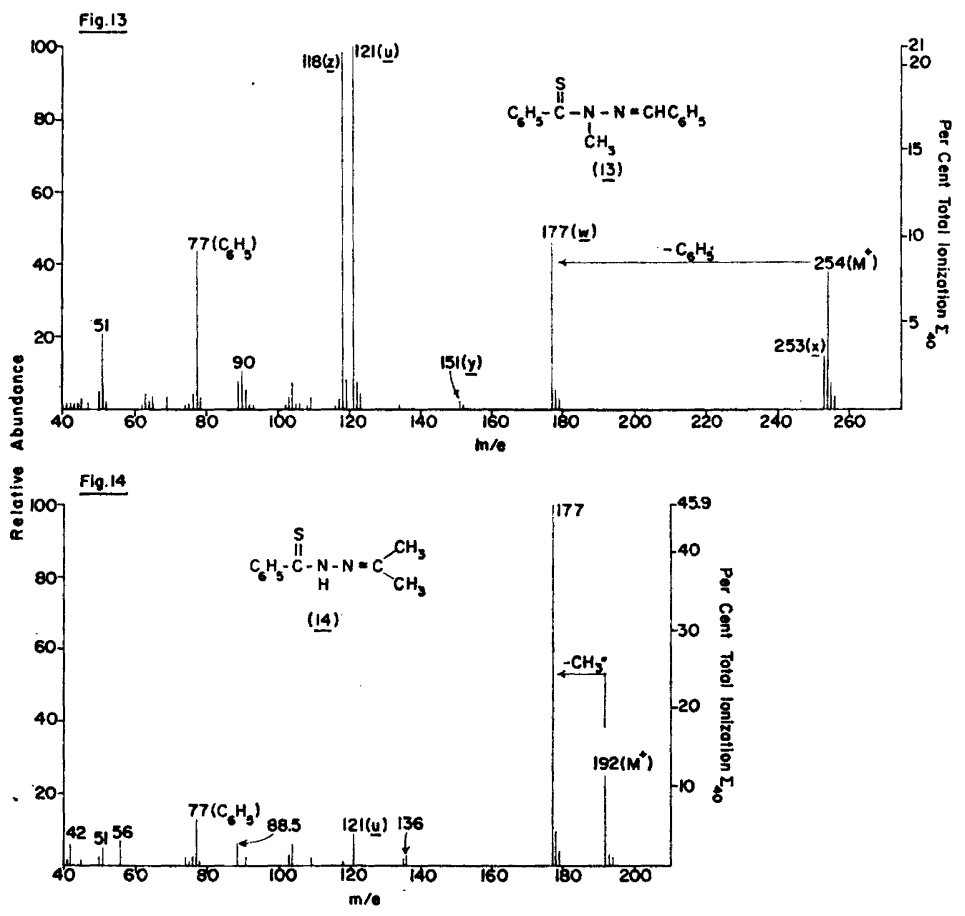

Acta Chem. Scand. 21 (1967) No. 8 
this genesis involves the breaking of a vinylic bond. These ions remained prominent at low electron energy and the driving force for this fragmentation must be the stability of the even-electron species $w$.<smiles>C=NN(C)C(=S)c1ccccc1</smiles>

In the case of compound 13 loss of a hydrogen atom from the molecular ion yields $x(m / e$ 253). Consistent with this formulation is the observation that acetone thiobenzhydrazone contains an $M-15$ ion in its spectrum (Fig. 14).

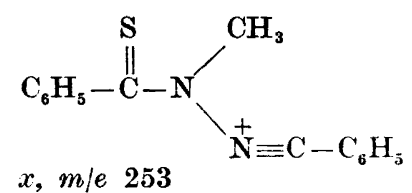

The base peak ( $m / e$ 121) in the spectrum (Fig. 13) of compound 13 is associated with the ion $u,\left(\mathrm{R}=\mathrm{C}_{6} \mathrm{H}_{5}\right)$, but at low electron energy this peak becomes virtually unrecognizable. This result indicates that $u$ arises not directly from the molecular ion but rather from a fragment ion. A plausible genesis would be $w \rightarrow u(m / e$ 121) in which rupture of the carbon-nitrogen bond is facilitated by allylic activation. No metastable ions could be detected for either $\mathrm{M}^{+} \rightarrow m / e 121$ or for the proposed fragmentation $w \rightarrow u$.

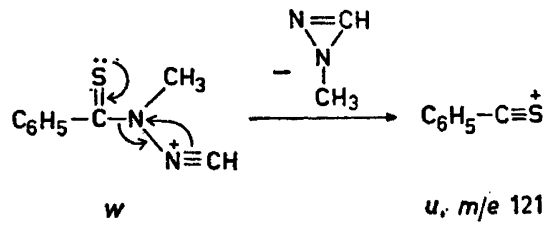

A weak peak at $m / e 151(M-103)$ in the spectrum (Fig. 13) of the thiohydrazone 13 corresponds to expulsion of benzonitrile as envisaged (McLafferty rearrangement $\left.{ }^{2}\right)$ by $13 \rightarrow y(m / e ~ 151)$ or by a four-centered intermediate (see $9 \rightarrow q)$.

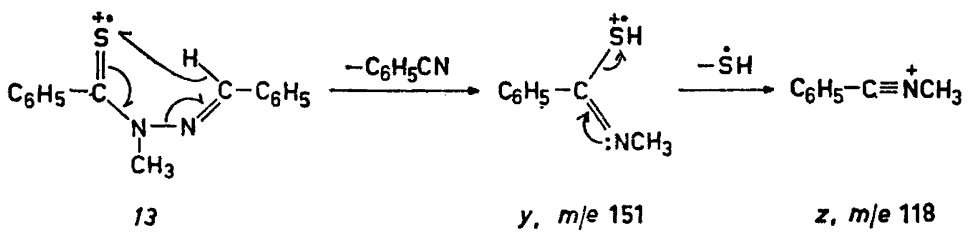


Further decomposition of $y$ by loss of a sulphydryl radical can yield $z$, $(m / e$ 118) the second most abundant ion in the spectrum (Fig. 13) of the thiohydrazone 13 . The results from high resolution mass spectrometry $\left(\mathrm{C}_{8} \mathrm{H}_{8} \mathrm{~N}\right)$ agree with the empirical composition assigned to the ion $z$. No metastable ion for the transition $y \rightarrow z$ was found while at low voltage $(19 \mathrm{eV})$ the ratio of the peaks at $m / e 118$ and 151 remained virtually identical to that found at $70 \mathrm{eV}$.

\section{EXPERIMENTAL}

The low resolution mass spectra were obtained with an Atlas $\mathrm{CH}-4$ instrument using the TO-4 ion source (direct sample introduction into the ion source) operating at $70 \mathrm{eV}$. Attempts to determine the mass spectra of the compounds reported in this paper with a Consolidated Electrodynamics Model 21-103C mass spectrometer using an all-glass heated inlet system $\left(200^{\circ}\right)$ resulted in sample decomposition. High resolution mass measurements were performed by Mr. R. G. Ross using an A.E.I. MS-9 instrument. The thiocarbonyl compounds were of analytical purity.

Acknowledgement. We are indebted to the U.S. Public Health Service for Grants Nos. GM-11309 and AM-04257 to Stanford University. The purchase of the Atlas CH-4 mass spectrometer was made possible by the National Aeronautics and Space Administration (Grant No. NsG 81-60).

\section{REFERENCES}

1. Budzikiewicz, H., Djerassi, C. and Williams, D. H. Mass Spectrometry of Organic Compounds, Holden-Day, San Francisco, Calif. 1967, Chapter 3.

2. McLafferty, F. W. Anal. Chem. 31 (1959) 82; For an extensive coverage, see section $3-7$ in Ref. 1 .

3. For a review of skeletal rearrangements in mass spectrometry see Brown, P. and Djerassi, C. Angew. Chem. 79 (1967) 481.

4. Thomson, J. B., Brown, P. and Djerassi, C. J. Am. Chem. Soc. 88 (1966) 4049; Madsen, J., Nolde, C., Lawesson, S.-O., Schroll, G., Bowie, J. H. and Williams, D. H. Tetrahedron Letters 1965 4377; see also chapters 7, 15, and 19 in Ref. 1.

5. Sandström, J. Acta Chem. Scand. 17 (1963) 678, 731, 937, 1380.

6. Spiteller, G. Monatsh. 92 (1961) 1147.

7. The mass spectra of 3-phenyl thioureas have been discussed. See Shapiro, R. H., Serum, J. W. and Duffield, A. M. J. Org. Chem. In press; Baldwin, M., Kirkien-Konasiewicz, A., Maccoll, A. and Saville, B. Chem. Ind. (London) 1966286.

Received April 29, 1967.

Acta Chem. Scand. 21 (1967) No. 8 